\title{
Origin of Palatability Coding in Medial Prefrontal Cortex
}

\author{
Ana Parabucki and Shai Netser \\ Sagol Department of Neurobiology, University of Haifa, Haifa, Israel 31905 \\ Review of Jezzini et al.
}

Gustatory processing starts with activation of taste receptors located in the oral cavity. Axons of these receptor cells project to the primary gustatory nucleus in the brainstem, and from there to the pons. In the following stage, taste information flows in two independent channels: through the amygdala and through the thalamus. Information from these two areas converges in the gustatory cortex (GC) - the most studied area of the gustatory system. Subsequently, GC projects to the orbitofrontal cortex (OFC) and medial prefrontal cortex (mPFC) (Simon et al., 2006). While the OFC has been proposed to serve as a secondary gustatory cortex, the involvement of the mPFC in taste processing is much less understood.

Much research has been directed toward understanding how taste quality is encoded in GC neuronal activity. Early studies of GC focused on the average firing rate of the response, neglecting temporal variability. However, activity evoked by different tastants can vary in latency, duration, and temporal pattern. Analysis of the temporal pattern of GC neural responses revealed that changes in firing rate arise from three distinct processes: (1) an early response related to detection, (2) a second phase that correlates with taste identity, and (3) delayed activity

Received Jan. 27, 2014; revised Feb. 17, 2014; accepted Feb. 19, 2014.

A.P. was supported by the EU through the Marie Curie Career Integration Grant No. 334341. We thank Roman Shusterman and Genela Morris for their useful comments.

Correspondence should be addressed to Shai Netser, Sagol Department of Neurobiology, Terrace Building 041, University of Haifa, Mount Carmel, Haifa, Israel 31905. E-mail: shainetser@gmail.com.

DOI:10.1523/JNEUROSCI.0362-14.2014

Copyright $\odot 2014$ the authors $\quad 0270-6474 / 14 / 344121-02 \$ 15.00 / 0$ corresponding to the pleasantness of the tastant (palatability) (Katz et al., 2001).

In contrast to $\mathrm{GC}, \mathrm{mPFC}$ responses to tastants have only been studied in the context of complex tasks. mPFC plays an important role in internally motivated behaviors, and it has recently been suggested to be specifically driven by consummatory behavior (Horst and Laubach, 2013). However, no studies have directly addressed whether mPFC encodes the chemosensory and hedonic aspect of tastes, regardless of the cognitive dimension. To close this gap, Jezzini and colleagues (2013) performed simultaneous recordings of electrophysiological activity in GC and $\mathrm{mPFC}$ in awake rats. They examined $\mathrm{mPFC}$ responses to tastants, and compared them to responses in GC.

To avoid a confounding cognitive context (i.e., the association of a tastant with a cue or the task), authors used passive delivery of tastants' solutions, after habituating the animals to calmly drink in a box. Four basic tastants were randomly delivered through intraoral cannulae: sucrose $(\mathrm{S})$, sodium chloride $(\mathrm{N})$, citric acid $(\mathrm{C})$, and quinine $(\mathrm{Q})$.

Detailed analysis of the data showed that the responses of $\mathrm{mPFC}$ neurons were indeed modulated by passive delivery of taste solutions, although to a lesser extent than GC neurons. Further comparison indicated that $\mathrm{MPFC}$ neurons displayed a smaller degree of taste selectivity. However, although mPFC neurons distinguished between tastes less successfully than GC, they were as efficacious in encoding palatability. Palatability-related responses (assessed as similarity among responses to $\mathrm{S}$ and $\mathrm{N}$, and similarity between $\mathrm{C}$ and $\mathrm{Q}$ ) were longer in $\mathrm{mPFC}$ than in GC. Furthermore, in contrast to GC, aversive stimuli induced stronger responses than appetitive ones in mPFC.

Jezzini and colleagues (2013) stress the importance of GC inputs to $\mathrm{mPFC}$ in coding the responses to tastes, but the amygdala may also have a role in this process. Input from the basolateral amygdala (BLA) to GC is required for representation of palatability in GC. Inactivation of the BLA selectively reduces the ability of GC to encode palatability, leaving the detection and identification phases unchanged (Piette et al., 2012). Previous studies have identified a specific subtype of taste-coding neurons in BLA that respond for a relatively long duration, similar to the duration of GC neuron responses (Fontanini et al., 2009). However, GC and BLA neurons display two distinct modes of temporal segmentation of information in their responses. While responses of GC neurons consist of "detection-identificationpalatability" phases, those of BLA neurons encode two phases: "detection" and "palatability" (Fig. 1).

Two areas in amygdala, BLA and the central nucleus, have been shown to respond to passive delivery of taste stimuli ( $\mathrm{Pi}$ ette et al., 2012; Sadacca et al., 2012). However, only the BLA sends afferent projections to the mPFC. This input is robust, innervating all four subdivisions of the mPFC (Hoover and Vertes, 2007). Therefore, we suggest the BLA as the main source of the hedonic responses observed in $\mathrm{mPFC}$.

Responses of neurons in the $\mathrm{mPFC}$ are longer than those in the GC (Jezzini et al., 


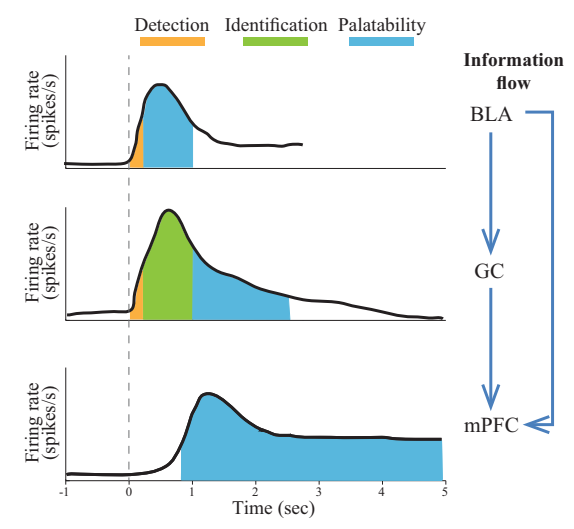

Figure 1. Palatability information flow in the BLA-GCmPFC circuit. The top panel is a schematic of typical peristimulus time histogram (PSTH) of long-responding neurons in the BLA (modified from Fontanini et al., 2009, their Fig. 2C). The middle and bottom panels illustrate the PSTH responses of GC and mPFC observed in Jezzini et al. (2013). The different colors indicate the information encoded during different periods of the responses. The scheme on the right illustrates the anatomical connections suggested to drive palatability information in $\mathrm{mPFC}$.

2013) and BLA (Fontanini et al., 2009). Palatability-related information appeared in these responses $\sim 1 \mathrm{~s}$ after stimulus onset, similar to in GC neurons, but lasted at least 5 s. Conversely, GC and BLA repre- sented palatability for $\sim 1 \mathrm{~s}$. The prolonged palatability phase seen in $\mathrm{MPFC}$ is, in our opinion, a result of integration of the inputs from both BLA and GC. Information from GC and BLA could contribute to $\mathrm{mPFC}$ responses in a complex manner, either consecutively (first BLA and then GC) or simultaneously (Fig. 1). In any case, this integration can yield longlasting palatability information, even when the responses of $\mathrm{mPFC}$ are relatively weak, due to summation of similar responses to pleasant and aversive stimuli.

Altogether, the inputs from the GC and BLA are potential sources for the innate pleasant and aversive responses seen in $\mathrm{mPFC}$ when processing goal-directed actions and reward-guided behaviors. Moreover, since both the GC and BLA have been shown to integrate information from additional sensory modalities (Fontanini et al., 2009; Samuelsen et al., 2012), it is possible that attractiveness or repulsiveness of stimuli from other modalities is also mediated by these pathways.

\section{References}

Fontanini A, Grossman SE, Figueroa JA, Katz DB (2009) Distinct subtypes of basolateral amygdala taste neurons reflect palatability and reward. J Neurosci 29:2486-2495. CrossRef Medline
Hoover WB, Vertes RP (2007) Anatomical analysis of afferent projections to the medial prefrontal cortex in the rat. Brain Struct Funct 212:149-179. CrossRef Medline

Horst NK, Laubach M (2013) Reward-related activity in the medial prefrontal cortex is driven by consumption. Front Neurosci 7:56. CrossRef Medline

Jezzini A, Mazzucato L, La Camera G, Fontanini A (2013) Processing of hedonic and chemosensory features of taste in medial prefrontal and insular networks. J Neurosci 33:18966-18978. CrossRef Medline

Katz DB, Simon SA, Nicolelis MA (2001) Dynamic and multimodal responses of gustatory cortical neurons in awake rats. J Neurosci 21 : 4478-4489. Medline

Piette CE, Baez-Santiago MA, Reid EE, Katz DB, Moran A (2012) Inactivation of basolateral amygdala specifically eliminates palatabilityrelated information in cortical sensory responses. J Neurosci 32:9981-9991. CrossRef Medline

Sadacca BF, Rothwax JT, Katz DB (2012) Sodium concentration coding gives way to evaluative coding in cortex and amygdala. J Neurosci 32:9999-10011. CrossRef Medline

Samuelsen CL, Gardner MP, Fontanini A (2012) Effects of cue-triggered expectation on cortical processing of taste. Neuron 74:410-422. CrossRef Medline

Simon SA, de Araujo IE, Gutierrez R, Nicolelis MA (2006) The neural mechanisms of gustation: a distributed processing code. Nat Rev Neurosci 7:890-901. CrossRef Medline 